\title{
Evaluating students" perceptions of the roles of mathematics in society
}

\begin{tabular}{|c|c|}
\hline $\begin{array}{l}\text { Toshikazu lkeda, Professor } \\
\text { of Mathematics Education } \\
\text { at Yokohama National } \\
\text { University, has found that while } \\
\text { mathematical modelling is } \\
\text { often evaluated with respect } \\
\text { to mathematical attributes, } \\
\text { little academic consideration } \\
\text { has been given to the non- } \\
\text { mathematical viewpoint. To fill } \\
\text { this knowledge void, he has } \\
\text { developed an analytical tool } \\
\text { to evaluate the changes in } \\
\text { students' perceptions of the } \\
\text { roles of mathematics in society } \\
\text { following an experimental } \\
\text { teaching program. }\end{array}$ & $\begin{array}{l}\text { aving students recognise the roles } \\
\text { that mathematics takes in society } \\
\text { is a significant aim in the teaching } \\
\text { and learning of mathematical modelling. } \\
\text { This issue has been considered by } \\
\text { academics since the } 1980 \text {. There have } \\
\text { been several studies investigating student } \\
\text { belief about the value of mathematics } \\
\text { in society, but little has changed in } \\
\text { the literature regarding the many roles } \\
\text { of mathematics in society. } \\
\text { CLASSIFICATION OF } \\
\text { MATHEMATICAL MODELS } \\
\text { Mathematical models are often classified } \\
\text { according to their various attributes: } \\
\text { whether they are concrete or abstract, } \\
\text { descriptive or analytical, together with } \\
\text { their underlying mathematical basis, such } \\
\text { as algebra, geometry or statistics. While } \\
\text { useful, these categories are essentially } \\
\text { founded on mathematical perceptions. } \\
\text { Toshikazu keda, a Professor of } \\
\text { Mathematics Education at Yokohama } \\
\text { National University, considers the non- } \\
\text { mathematical viewpoint in his study }\end{array}$ \\
\hline
\end{tabular}

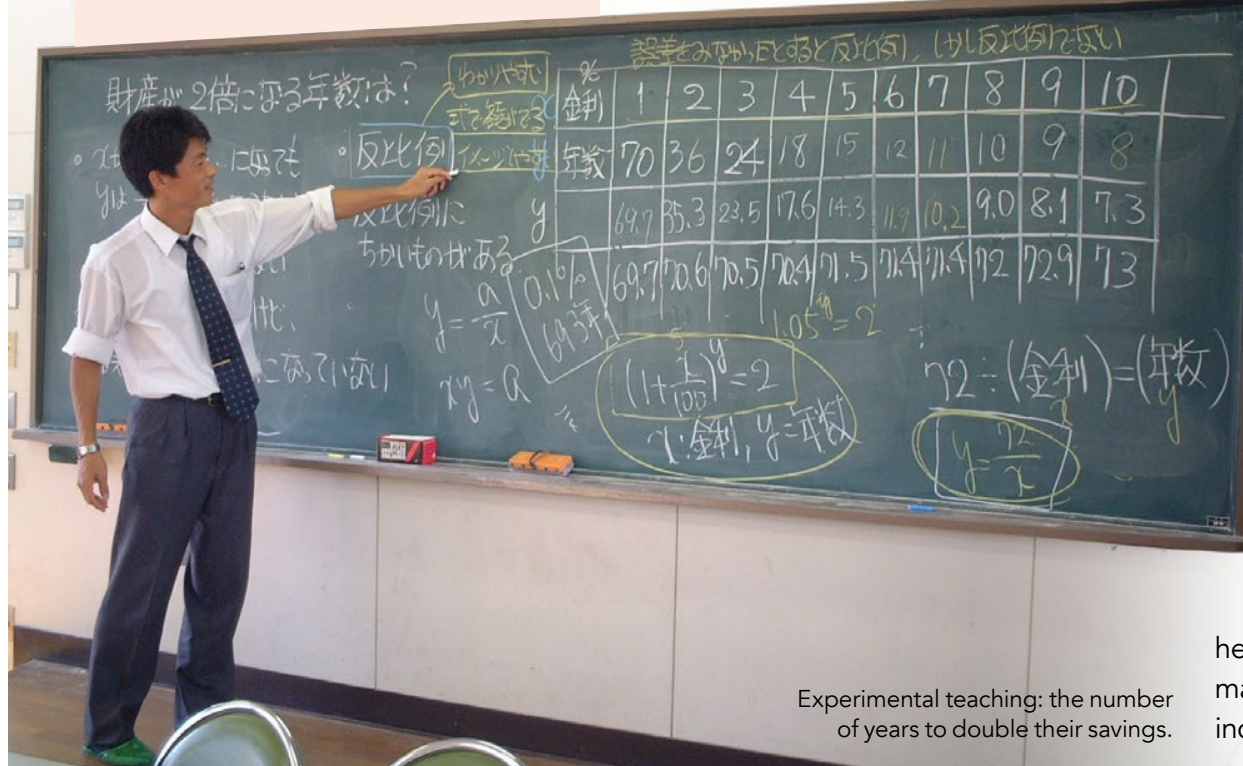

and has developed an analytical tool to assess how students perceive the roles of mathematics in society.

\section{METHODOLOGY}

The Likert-scales method, where items to 'strongly disagree', is often used to 'msess student' awis is of mathematics is in the real world. While this is a simple and effective tool, it does not capture detailed information regarding students' perceptions of the roles mathematics in society.

Professor lkeda has developed four categories which are centred on why mathematical models are used in socie These combine three standpoints. personal-societal perspectives, clarity of role statements, and specific-general contexts.

\section{CATEGORIES}

the first category, students see a personal pespetive. For from ( carrying out their personal financial calculations, but ignore the impact on society.

The second category has students adopting some social perspective; specific. For instance, they will acknowledge that mathematics is useful in society but not mention how it is useful or provide examples.

In the third category, students assume a societal viewpoint and refer to a specific context, such as how mathematics can manufacturing costs, but they do not include a general context.

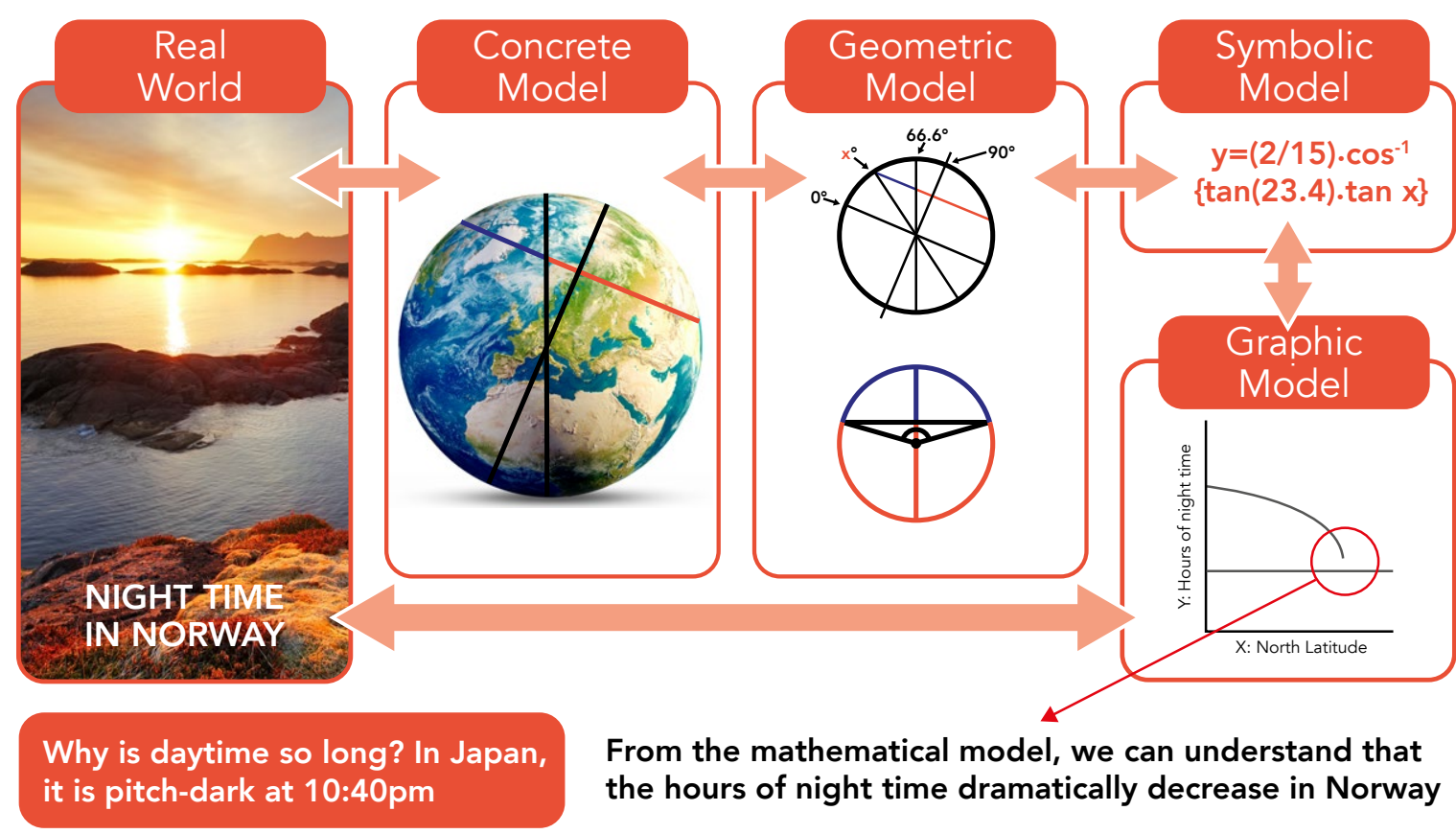

The fourth category has students adopting a societal perspective and referencing a general context, such as using mathematics to explain phenomena, contribute to decision making, or assist with designing objects.

\section{INVESTIGATION}

Professor lkeda conducted an experimental program with a ninth-grade class of approximately 30 students. The 2007-2008) a a jur high scho (2007-2008) at a junior high school in ears. A teaching program comprising hine lessons was devised These lessons took place once a week from September to November each year and were carried out by the classroom teacher. The first eight lessons each lasted 100 minutes and the ninth lesson took 50 minutes.

\section{THE EXPERIMENTAL}

\section{TEACHING PROGRAM}

The program of lessons concentrated on three roles of mathematics in society: understanding, making decisions, and designing. Eight modelling tasks were selected. The 'understanding' tasks involved investigating reflections of a face in a mikorand calculating probabilis recisions'
Having students recognise the roles that mathematics takes in society is a significant aim in the teaching and learning of mathematical modelling. a bank interest system, calculated the number of years to double their tennis serves. The 'designing' tasks cans, exploring the structure of a bicycle ector and designing a parking space.

The students were asked to write down their responses to the pre-program question: 'How is mathematics useful

TO MAKE MONEY DOUBLE savings and explored the position of when we examine real-world problems fom various perspectives?' before commencing the program of nine lessons During the first seven lessons, the teacher conducted group discussions regarding followed by problem-solving periods where the teacher presented one of the modelling problems. The students worked on the problem in groups of 4 or 5 and
VALUE OF A

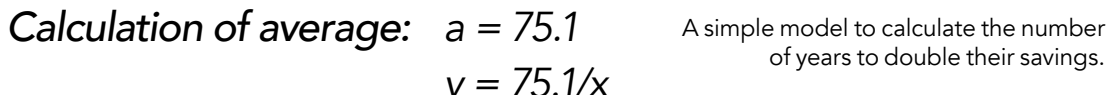


then came together to discuss it as a class In the seventh and eighth lessons, three of students selected one to work

Throughout the lessons, emphasis was put on the reason for solving problems
and students were encouraged to reflect on the roles of mathematics in order to identify the significant aspects of the roles of mathematics in society. The students first reflected prior to the teaching program; followed by reflection after each lesson; and finally, after the teaching program was completed.

During the ninth lesson, the students reviewed the eight modelling tasks. They reflected on the modelling processes and identified the common points in order to ascertain the roles of mathematics. The fudents discussed the problems they solved them. The students then broke into groups to the post-program question 'How is mathematics useful when we examine real-world problems from various perspectives?'. Then the teacher asked each of the students to write down their answer without any teacher-led discussio so that the students could provide their own answers supported by their group discussion, but without any influence from the teacher.

\section{ANALYSIS}

A total of 57 students took part in the study, 31 students during the first year The student' spong to the pre The students' esponses to the pre- and perception of the roles of mathematics in society were coded and then analysed Ikeda's analytical tool revealed that students' opinions concerning the roles of mathematics in society changed significantly over the course of the nine week experimental teaching program.

Analysis of the students' perception relating to personal-societal perspectives, clarity of role statements, and specific-

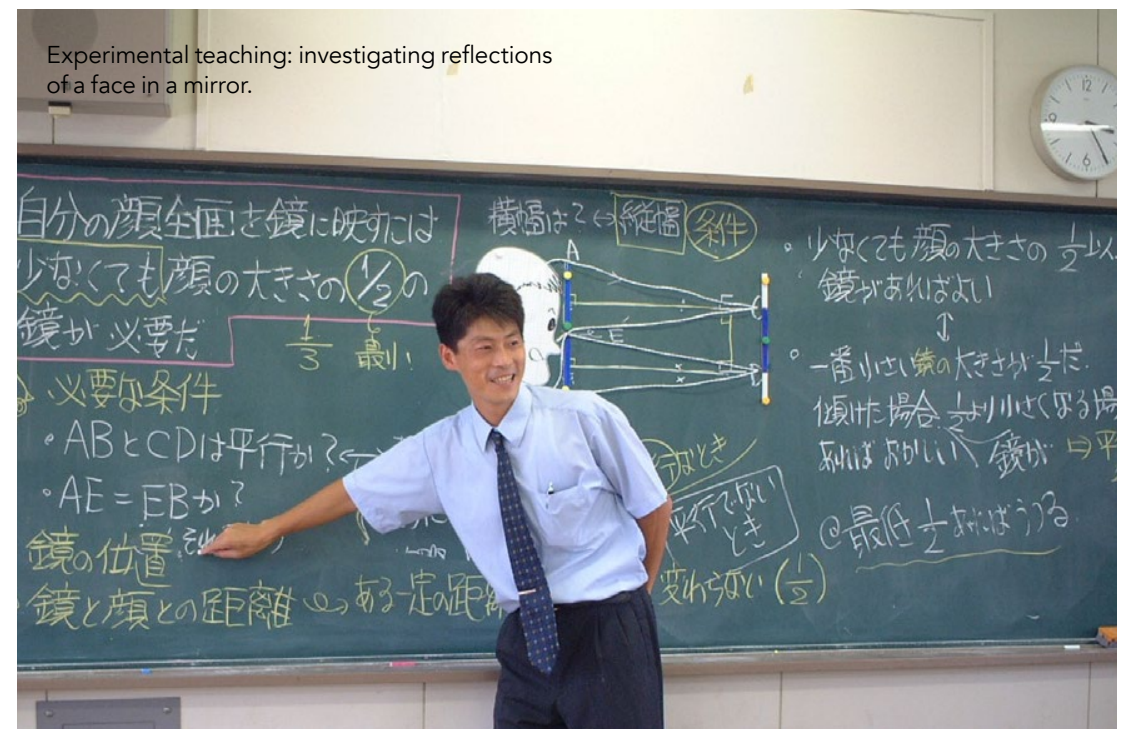

CONCLUSION

general contexts was carried out. A few dents continued to adhere only to the statements, insisting that mathematics was not useful in their lives, even thoug they acknowledged that it might be useful or others.

With respect to the personal-societal perspective, only a few students adopted a personal perspective without also developing a societal perspective. Regarding the clarity of role statements, several students still only used vague, general statements. From the specificgeneral contexts, the analytical tool revealed that some students were able to clearly identify several purposes of mathematical modelling.

Professor lkeda found that by using the analytical tool he could start to distinguish between the qualitative
differences of the various students' perceptions of the roles of mathematics in society as well as whether students were able to appreciate the roles from both personal and societal perspectives or only a personal perspective. He also discovered that students, who were able to perceive the roles of mathematics in society, did not automatically appreciate the utility of mathematics.

Students" opinions concerning the roles of mathematics in society changed significantly over the course of the nineweek experimental teaching program.
Professor lkeda found strong evidence program is significantly effective in developing students' thinking and their appreciation of mathematical modelling This was reinforced when he examined the work that students produced in the study, demonstrating their thoughts on solving the set tasks. lkeda found that these written examples of students' thinking consistently demonstrated a marked increase in the quality the mathematical modelling process.

This study also revealed that Professo keda's analytical tool enabled the clarification of students' perceptions of 列 before and after the teaching program students' perceptions regarding the roles and utilisation of mathematics in society changed significantly over the course of the nine-week teaching program.

Professor lkeda recommends that further attention should be paid to both the tool, particularly when setting up the pre- and post-program question and interpreting of the students' response. He suggests that samples of students are interviewed to check the validity mind, this analytical model still merits further use in future studies, particularly those involving student belief regarding
the value of mathematics in society. and depth of the students' insight into validity and reliability of his analytical of the results. Keeping these points in

Behind the Research

\section{Professor Toshikazu Ikeda}

E: toshi@ynu.ac.jp T: $\pm 81453393371 \quad$ W: http:///er-web.jmk.ynu.ac.jp/html//KEDA Toshikazu/en.htm W: www.researchgate.net/profile/Toshikazu lkeda W: https://sideplayer.com/slide/8309101/

Research Objectives

Toshikazu lkeda, Professor of Mathematics Education at Yokohama National University, work focuses on teaching mashematical modelly wand its applications. the changes in students' perceptions of the roles of mathematics in society following an experimental teaching program

Detail

Yokohama National University

40-8501 Kanagawa Prefecture

Yokohama, Hodogaya-ku,

Japan

Toshikazu lkeda is a Professor of Mathematics Education t Yokohama National University. He received his $\mathrm{PhD}$ in ducation at Waseda University in 2014. Since 1999, he has studied the teaching of mathematical modelling and applications, funded by a Grant-in-aid for Science Research

Funding

Gerienting Japar

YNU 横浜国立大学 Initiative for Global Arts \& Sciences

\section{References}

Ikeda, T. (2018). 'Evaluating student perceptions of the roles of mathematics in society following an experimental teaching program. ZDM Mathematics Education, 50(1-2), 259-271.

Ikeda,T. and Stephens, M. (2010). 'Three teaching principles for fostering students' thinking about modelling: An experimental teaching program for 9 grade students in 2(1). 49-59. Available at: htr.//proxyfurb br/ojs/index php/ modelling [accessed 02/01/19]

Ikeda,T. (2009). 'Didactical Reflections on the teaching of mathematical modelling-Suggestions from concepts of 'time' and 'place". In Morten Blomhøj and Susana Carreira, Roskilde University, Department of Science, Systems and Models,
Mathematical applications and modelling in the teaching and learning of mathematics, 217-228. IMFUFA tekst nr.461.

Ikeda, T., \& Stephens, M. (2017). 'Modelling as interactive translations among plural worlds: Experimental teaching using the night-time problem. In G.A. Stillman, W. Blum, \& G. Kaiser (Eds.), Mathematical modelling and applications - Crossing and researching boundanies in mathe pulics ed (pp.399-409), Springer International Publishing.

\section{Personal Response}

\section{What initially prompted you to investigate students'} perceptions of the roles of mathematics in society?

II In Japan, there has been the tendency where students from the result of PISA. To overcome this tendency, mathematical modelling has been gradually emphasised in the teaching of mathematics. However, l am uncertain that students will realise the usefulness of mathematics by focusing on mathematical modelling in mathematics be used in his/her future life, he/she might not realise the usefulness of mathematics even though he/she real ses that mathematics is applied in the real world. This study starts from this question 